\title{
Variability and Heritability of Morphological Traits in Collection of Cotton Genotypes (Gossypium hirsutum L.) and Their Potential Use for the Selection
}

\author{
M. C. Djaboutou \\ M.G. Sinha
}

Institut National des Recherches Agricoles du Bénin, Centre de Recherches Agricoles Coton et Fibres

\author{
S.S. Houedjissin \\ G.H. Cacai \\ C. Ahanhanzo
}

Département de Génétique et des Biotechnologies de la Faculté des Sciences et Techniques de l'Université d'Abomey-Calavi, Bénin

\section{doi: 10.19044/esj.2016.v13n3p385 URL:http://dx.doi.org/10.19044/esj.2016.v13n3p385}

\begin{abstract}
This study was conducted to estimate variability and heritability of some morphological traits available in 14 introduced cotton genotypes. The experiment was carried out in randomized complete block design with three replications. The experimental site is based in Cotton and Fibres Center for Agricultural Research at Cana located in the south of Republic of Benin.Analysis of variance showed highly significant differences among the 14 cotton genotypes $(p<0.001)$. The results showed high heritability for plant height, plant height to first fruiting branch, number of vegetative branches, length of vegetative branch, length of fruiting branch, number of fruiting branches and number of nodes among 14 varieties. Heritability values vary from 0.720 (NFB) to 0.999 (PH and LVB).Positive correlations were found between plant height and length of fruiting branch and number of fruiting branches and other morphological characters. A highly significant correlation $(r=0.80)$ was observed between plant height to first fruiting branch and plant height. The relatively high variability and heritability estimates for morphological traits suggested that they could be used in breeding programs.
\end{abstract}

Keywords: Gossypium hirsutum, fruiting branch, vegetative branch, heritability, variability 


\section{Introduction}

Cotton (Gossypiumhirsutum L.) is very imperative non-food economy oriented fiber and cash crop of Benin.Cotton network constitutes the main source of national economic increase and constitutes a strong strategic tool to fight against the poverty (INRAB, 2013). Benin, through Cotton and Fiber Center for Agricultural Research, has more than 100 genotypes cotton currently in its Genebank. Although there is a big source of variability for breeding and good collections of G.hirsutum in Benin cotton Genebank, no information is available on the variability and heritability of their morphological characters. However the selection should be more efficient if morphological as well as physiological characteristics are identified and used as criteria of sifting in the classic process of plants improvement (Hamliet al., 2015). Several characters are reported in the literature like having a more or less close connection with the tolerance or the performance of the plants under conditions of stress. Among these characters appear fruiting branches, vegetative branches, plant height to first fruiting branch, main stem of plant and nodes. Thus, according to Khalil et al. (2015), plant traits such as plant height play an important role in the sustainable pest management of cotton crop. It is therefore imperious to evaluate the variability and the heritability of these characters within Benin cotton Genbank in order to assure their stability in the descent. Morphological characteristics are used by breeders in the development of improved cultivars. The evaluation of genetic variability available is a preparatory to start a program of selection and particularly to choose the parents to be crossed (Hamli et al., 2015). In the same way, the heritability of the characters determines the response to the selection and depends on the genetic material studied as well as experimental device (Sekloka, 2004; Shukla et al., 2006; Atta et al., 2008).

Keeping in view the work of above scientists, the present study was conducted to investigate genetic diversity and heritability of fourteen (14) genotypes of cotton using morphological marker.

\section{Materials and methods Genetic materials}

Fourteen genotypes of cotton (Gossypium hirsutum L.) were chosen from the collection in the field for analysis in this experiment (table1) as they presented interesting divers forms and maturenesses. The collection in the field of cotton plants laid within the experiment site of Cotton and Fibres Center for Agricultural Research at Cana $\left(2^{\circ} 5^{\prime} \mathrm{E}, 7^{\circ} 6^{\prime} \mathrm{N}\right)$ located in south of Republic of Benin at an altitude of about 89 meters above sea level. 
Table1: Qualitative description of the 14 cotton genotypes studied

\begin{tabular}{|c|c|c|}
\hline Genotypes & Origins & Characteristics \\
\hline A24 & Tchad (CIRAD/ITRA) & Slender shrub, leaves of lobed form, small boll \\
\hline CD14 & Zambia(CIRAD/MNRWD) & Slender shrub, broad to lobed leaves, medium boll \\
\hline Chaco 520 & Argentina & Compact shrub, leaves of lobed form, big boll \\
\hline CR 92-498 & Costa-Rica (CIRAD) & Slender and bush shrub, broad to lobed form, big boll \\
\hline CR 92-534 & Rica (CIRAD) & Slender shrub, trend to bend, lobed leave, medium boll \\
\hline CS 189 & Australia (CSIRO) & Bush to compact shrub, broad leave, medium boll \\
\hline Deltapine 90 & USA (Deltapine) & Bush shrub, broad to lobed leave, medium boll \\
\hline Guazuncho II & Argentina & $\begin{array}{l}\text { Bush to compact shrub, broad to lobed leave, medium to } \\
\text { big boll }\end{array}$ \\
\hline Н 279-1 & Togo (CIRAD/ITRA) & Slender shrub, broad to lobed leaves, medium boll \\
\hline Irma 772 & Dun (CIRAD/IRAD) & Slenc \\
\hline Irma Blt-pf & Cameroun (CIRAD/IRAD) & $\begin{array}{l}\text { Slender shrub, trend to bend, broad leave, medium to big } \\
\text { boll }\end{array}$ \\
\hline Irma Z 856 & Cameroun (CIRAD/IRAD) & Bush to slender shrub, broad leave, medium boll. \\
\hline Nta 88-6 & Mali (CIRAD/IER) & Slender shrub, broad to lobed leaves, medium to big boll \\
\hline Sicala 34 & Australia (CSIRO) & Compact shrub, broad leave, small boll \\
\hline
\end{tabular}

\section{Morphological characteristics}

Seven morphological traits were measured in the field experiments on the all 14 genotypes. Eight plants were selected randomly from each genotype and morphological characters were described during three years 2009, 2010 and 2011. Measurements were made on plant height to first fruiting branch (PHFFB); number of vegetative branches (NVB); plant height (PH); length of vegetative branch (LVB); length of fruiting branch (LFB); number of fruiting branches (NFB) and number of nodes (NN).

\section{Field evaluation}

Plots were single rows, $10 \mathrm{~m}$ in length and $1 \mathrm{~m}$ apart with $0.50 \mathrm{~m}$ plant spacing. The seeds were sown at the end of June with one genotype per row. The seedlings were thinned to 1 plant per hill 3 weeks after sowing. The N.P.K. fertilizer was applied at thinning with the rate of $200 \mathrm{~kg} / \mathrm{ha} 21$ days after emergence and $N$ fertilizer was applied with the rate of $50 \mathrm{~kg} / \mathrm{ha} 40$ days after sowing. Insect pest was controlled using ten fortnightly sprays of binaries accaricid and binaries aphicid pesticides.

\section{Data analysis}

Cotton genotypes were planted in a randomized complete block design (RCBD) or bloc of Fisher with three replications.. Statistical analyzes of the results were performed with the STATISTICA software, version 6 (www.statsoft.com) and R (Version 3.1). Canonical discriminant analysis step (stepwise canonic analysis) was performed on the morphological variables prior to selection of the most discriminating variables. It was 
followed by a second canonical discriminant analysis to describe, through a system of axes, genotypes based on variables selected by the canonical discriminant analysis step. Then, analysis of variance followed by tests comparing averages by the test and Newman Keuls were used to characterize the genotypes from the average of their different morphological characters and compare the observed variability of a genotype to another. Heritability genotypic $\left(\mathrm{h}_{\mathrm{sb}}^{2}\right)$ and genetic advance (GA) of genotypes morphological characters were also estimated in order to assess the proportion of the phenotypic variability of genetic origin which is heritable and fixable in whole or in part.

Cluster analysis using Unweighted Paired Group Mean Average (UPGMA) was also performed to create a dendrogram and group the morphologically similar genotypes. Principal component analysis (PCA) based on morphological characters was also conducted to investigate the relationship between the different genotypes of cotton.

\section{Results}

\section{Discrimination of the cotton genotypes based on morphological characteristics}

Univariate analysis showed a significant variability $(\mathrm{p}>0,05)$ among the genotypes for all morphological traits (Table 2).The canonical analysis revealed that all seven morphological variables best discriminated the different genotypes. The results of inferential tests (table 3) confirmed the discriminating power of these variables because they showed that, for all of them, there are very highly significant differences ( $p$ / Wilk's Lambda $<0.0001$ ) between genotypes.The canonical discriminant analysis showed that the axis 1 (or first canonical discriminant axis) was strongly correlated with variables PHFFB, NVB, LVB, LFB, NFB and NN, while axis 2 best discriminated genotypes on the basis of the variable $\mathrm{PH}$ (table 4). It would therefore be possible to make a fairly accurate description of 14 genotypes from these morphological variables.

Table 2: Univariate tests performed on morphological variables according to different genotypes of cotton

\begin{tabular}{ccccc}
\hline Variables & SC & MC & F & P \\
\hline PHFFB & 449,19 & 34,55 & 28,97 & $0,000^{* * *}$ \\
NVB & 10,2279 & 0,7868 & 5,453 & $0,000^{* * *}$ \\
PH & 13585,1 & 1045,0 & 443,6 & $0,000^{* * *}$ \\
LVB & 4994,5 & 384,2 & 251,9 & $0,000^{* * *}$ \\
LFB & 2918,97 & 224,54 & 206,13 & $0,000^{* * *}$ \\
NFB & 47,83 & 3,68 & 3,42 & $0,003^{* *}$ \\
NN & 75,27 & 5,79 & 2,77 & $0,011^{*}$ \\
\hline
\end{tabular}

$\mathrm{PHFFB}=$ plant height to first fruiting branch; $\mathrm{NVB}=$ number of vegetative branches;

$\mathrm{PH}=$ plant height; $\mathrm{LVB}=$ length of vegetative branch; $\mathrm{LFB}=$ length of fruiting branch; NFB= number of fruiting branches; $\mathrm{NN}=$ number of nodes 
Table 3: Canonical analysis on morphological variables to determine the most discriminating variables to compare the different genotypes.

\begin{tabular}{ccccc}
\hline Variables & F value & $\begin{array}{c}\text { Partial } \\
\text { (Lambda) }\end{array}$ & Wilk's Lambda & p $<$ Lambda \\
\hline PHFFB & 10,54459 & 0,138295 & 0,000000 & $0,000^{* * *}$ \\
NVB & 4,55407 & 0,270926 & 0,000003 & $0,000^{* * *}$ \\
PH & 63,89030 & 0,025804 & 0,000605 & $0,000^{* * *}$ \\
LVB & 54,25153 & 0,030250 & 0,017038 & $0,000^{* * *}$ \\
LFB & 37,31082 & 0,043389 & 0,124563 & $0,000^{* * *}$ \\
NFB & 3,31340 & 0,338075 & 0,477968 & $0,006^{* *}$ \\
NN & 4,74513 & 0,262885 & 0,822341 & $0,000^{* * *}$ \\
\hline
\end{tabular}

PHFFB=plant height to first fruiting branch; $\mathrm{NVB}=$ number of vegetative branches;

$\mathrm{PH}=$ plant height; $\mathrm{LVB}=$ length of vegetativebranch; $\mathrm{LFB}=$ length of fruiting branch; NFB= number of fruiting branches; $\mathrm{NN}=$ number of nodes

Table 4: Canonical discriminant analysis on morphological variables according to different genotypes

\begin{tabular}{ccc}
\hline & Racine1 (68,42\%) & Racine2 (27,26\%) \\
\hline PHFFB & 0,8264 & $-0,7830$ \\
NVB & 0,6126 & 0,4463 \\
PH & $-0,4728$ & $-1,2071$ \\
LVB & $-1,0997$ & 0,6744 \\
LFB & $-1,0620$ & 0,6687 \\
NFB & $-0,5706$ & 0,3070 \\
NN & 1,1051 & $-0,3023$ \\
\hline
\end{tabular}

PHFFB=plant height to first fruiting branch; $\mathrm{NVB}=$ number of vegetative branches;

$\mathrm{PH}=$ plant height; $\mathrm{LVB}=$ length of vegetative branch; $\mathrm{LFB}=$ length of fruiting branch; NFB= number of fruiting branches; $\mathrm{NN}=$ number of nodes

\section{Morphological descriptors}

Statistical analysis of variables of table 5 revealed highly significant variability among the 14 genotypes. The plant height varied from $92,1 \pm 0,06$ $\mathrm{cm}$ (Chaco 520) to 147,0 $\pm 1,15 \mathrm{~cm}$ (Irma Blt-pf), plant height to first fruiting branch varied from $19,0 \pm 0,28 \mathrm{~cm}$ (Sicala 34) to29,5 $\pm 0,28$ (Nta 88-6), the longest of vegetative branches from $50 \mathrm{~cm}$ ( Chaco 520) to $95 \mathrm{~cm}$ (A 24), the longest fruiting branches from $33,5 \pm 0,87 \mathrm{~cm}$ (Chaco 520 ) to $70,3 \pm 0,68 \mathrm{~cm}$ (A 24), number of fruiting branches from 14,8 $\pm 0,86$ ( Chaco 520) to $18,6 \pm 0,34$ (H279-1), number of vegetative branches from 1,4 $\pm 0,12$ (Guazuncho II) to 3,4 $\pm 0,28$ (A 24), number of node on main-stem from

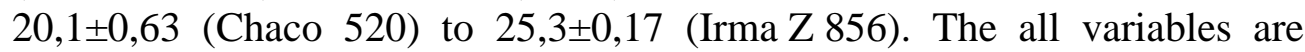
highly significantly heritable and vary from 0.720 (NFB) to 0.999 (PH and LVB). 
Table 5: Analysis of variance and genotypic heritability performed on morphological variables studied according to different genotypes of cotton

\begin{tabular}{cccccccc}
\hline Génotypes & PHFFB & NVB & PH & LVB & LFB & NFB & NN \\
\hline A 24 & $21,2 \pm 1,04$ & $3,4 \pm 0,28$ & $129,7 \pm 0,33$ & $96,9 \pm 0,38$ & $70,3 \pm 0,68$ & $16,3 \pm 0,28$ & $23,4 \pm 0,90$ \\
CD 14 & $23,7 \pm 0,40$ & $2,2 \pm 0,17$ & $124,4 \pm 0,75$ & $68,0 \pm 1,15$ & $40,5 \pm 0,58$ & $16,3 \pm 0,34$ & $22,8 \pm 0,80$ \\
Chaco 520 & $19,5 \pm 1,15$ & $1,8 \pm 0,29$ & $92,1 \pm 0,06$ & $50,9 \pm 0,81$ & $33,5 \pm 0,87$ & $14,8 \pm 0,86$ & $20,1 \pm 0,63$ \\
CR 92-498 & $21,3 \pm 0,75$ & $1,9 \pm 0,23$ & $106,6 \pm 0,81$ & $62,7 \pm 0,63$ & $40,3 \pm 0,17$ & $16,2 \pm 0,69$ & $22,3 \pm 1,15$ \\
CR 92-534 & $24,9 \pm 1,10$ & $2,2 \pm 0,17$ & $123,9 \pm 1,27$ & $67,2 \pm 0,69$ & $43,1 \pm 0,57$ & $15,9 \pm 0,05$ & $21,9 \pm 0,11$ \\
CS 189 & $19,3 \pm 0,17$ & $1,9 \pm 0,23$ & $94,4 \pm 0,23$ & $65,0 \pm 0,86$ & $41,0 \pm 0,57$ & $15,9 \pm 0,17$ & $21,9 \pm 1,04$ \\
Dp 90 & $20,3 \pm 0,17$ & $2,1 \pm 0,06$ & $102,6 \pm 1,15$ & $66,7 \pm 0,75$ & $39,4 \pm 0,34$ & $16,3 \pm 0,17$ & $22,0 \pm 0,57$ \\
Guazuncho II & $17,2 \pm 0,69$ & $1,4 \pm 0,12$ & $96,9 \pm 0,98$ & $55,3 \pm 0,17$ & $40,1 \pm 0,57$ & $16,8 \pm 1,39$ & $22,1 \pm 1,79$ \\
H 279-1 & $21,8 \pm 0,46$ & $1,9 \pm 0,23$ & $124,2 \pm 1,27$ & $73,5 \pm 0,75$ & $51,9 \pm 1,10$ & $18,6 \pm 0,34$ & $21,9 \pm 0,92$ \\
Irma 772 & $22,2 \pm 0,05$ & $1,6 \pm 0,12$ & $140,1 \pm 0,64$ & $77,0 \pm 1,15$ & $46,8 \pm 0,11$ & $18,3 \pm 0,98$ & $24,5 \pm 0,28$ \\
Irma Blt-pf & $25,9 \pm 0,52$ & $2,1 \pm 0,1$ & $147,0 \pm 1,15$ & $76,1 \pm 0,05$ & $50,0 \pm 0,57$ & $18,5 \pm 0,28$ & $24,4 \pm 0,23$ \\
Irma Z 856 & $26,3 \pm 0,17$ & $2,6 \pm 0,2$ & $123,1 \pm 1,21$ & $72,8 \pm 0,46$ & $42,7 \pm 0,17$ & $17,6 \pm 0,23$ & $25,3 \pm 0,17$ \\
Nta 88-6 & $29,5 \pm 0,28$ & $2,6 \pm 0,29$ & $143,4 \pm 0,81$ & $81,0 \pm 0,28$ & $46,1 \pm 0,63$ & $17,0 \pm 0,57$ & $23,8 \pm 0,75$ \\
Sicala 34 & $19,0 \pm 0,28$ & $1,6 \pm 0,17$ & $102,1 \pm 0,06$ & $64,3 \pm 0,75$ & $46,1 \pm 0,63$ & $16,4 \pm 0,23$ & $21,8 \pm 0,57$ \\
\hline Moyenne & $22,3 \pm 0,53$ & $2,09 \pm 01$ & $117,9 \pm 2,8$ & $69,8 \pm 1,71$ & $45,1 \pm 1,31$ & $16,7 \pm 0,21$ & $22,7 \pm 0,27$ \\
EcTyp. & 3,431 & 0,589 & 18,28 & 11,08 & 8,48 & 1,379 & 1,807 \\
$\mathrm{~h}^{2}$ bs & $0,984 * * *$ & $0.963^{* * *}$ & $0.999 * * *$ & $0.999 * * *$ & $0.997 * * *$ & $0.720 * * *$ & $0.880^{* * *}$ \\
GG\% & 6,95 & 1,168 & 37,619 & 22,80 & 17,416 & 2,045 & 3,275 \\
P>F & $0,000 * * *$ & $0,000^{* * *}$ & $0,000^{* * *}$ & $0,000^{* * *}$ & $0,000^{* * *}$ & $0,000 * * *$ & $0,000^{* * *}$ \\
\hline
\end{tabular}

$\mathrm{PHFFB}=$ plant height to first fruiting branch ; $\mathrm{NVB}=$ number of vegetative branches ; $\mathrm{PH}=$ plant height ; LVB=length of vegetative branch ; LFB= length of fruiting branch; $\mathrm{NFB}=$ number of fruiting branches ; $\mathrm{NN}=$ number of nodes ;

\section{Classification of cotton genotypes based on morphological characters}

UPGMA cluster of the 14 genotypes revealed interesting associations based on morphological characters. Cotton genotypes are grouped into two main clusters (figure 1). The first cluster contained 9 genotypes and the second 5 . Similarity index of the cluster was $<5 \%$, indicating the reliability of the clusters to the original data. Principal component analysis (PCA) based on morphological characters showed that the first two axes make up $80.88 \%$ of the total variance (figure 2). On the first axis, all the morphological characters had the highest variance. Moreover, it is interesting to note that principal component analysis classified alsocotton genotypes into two groups. However, PCA had not shown significant difference among genotypes. The first group contained 13 genotypes and the second 1 (A 24). Genotype A 24 was placed in more distant and so can be used in selection or in hybridization programs to produce heterosis with interesting characters. 


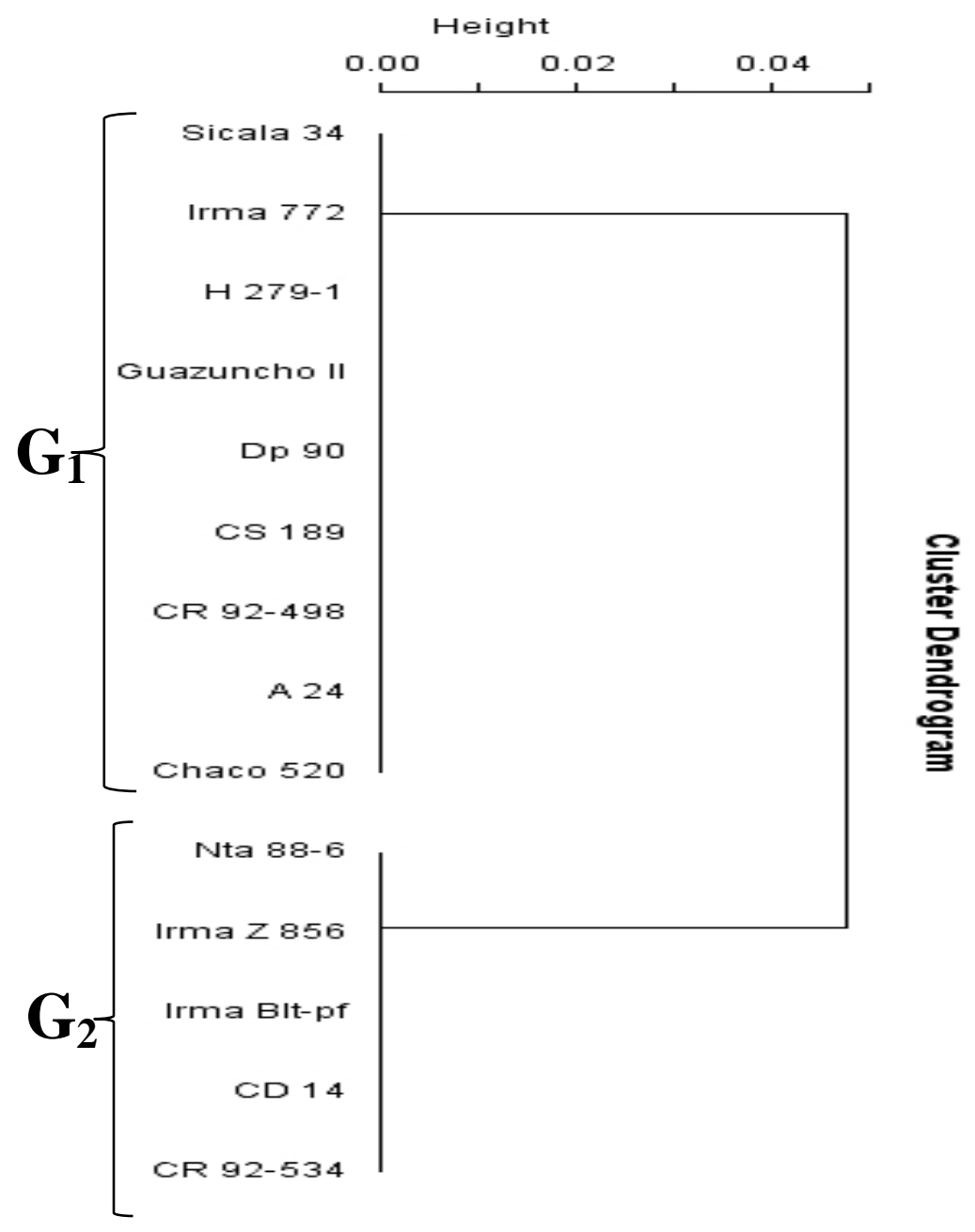

Figure 1: UPGMA cluster of genotypes based on morphological characters 


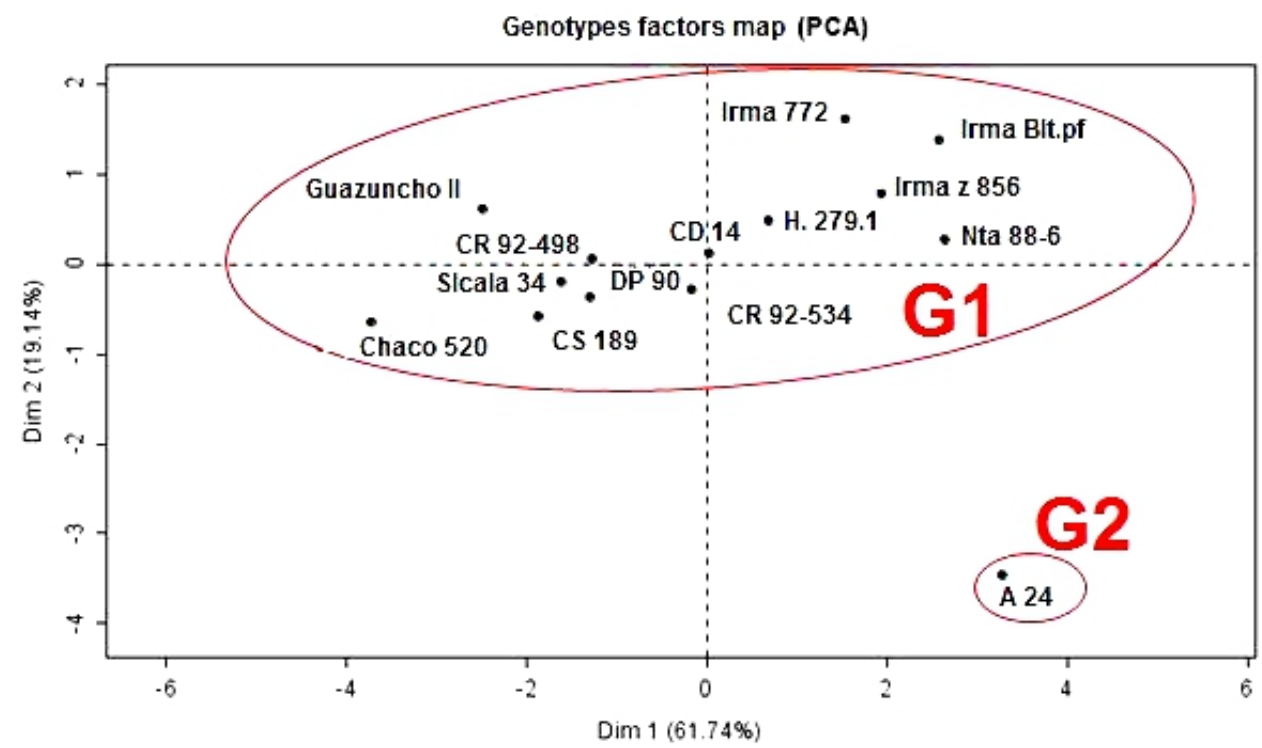

Figure 2: PCA based on morphological characters

\section{Correlation determined for morphological characters}

The coefficient of correlation determined for morphological characters showed a high significant positive correlation between plant height to first fruiting branch and plant height with number of nodes, number of vegetative branches with length of vegetative branch and length of fruiting branch, plant height and length of vegetative branch and number of fruiting branches with number of nodes, number of fruiting branches and number of nodes. However, the correlations were no significant between the plant height and number of vegetative branches, plant height to first fruiting branch and number of vegetative branches (table 6).

Table 6: Correlation of Pearson between morphological characters

\begin{tabular}{|c|c|c|c|c|c|c|c|}
\hline & PHFFB & NVB & PH & LVB & LFB & NFB & $\mathbf{N N}$ \\
\hline PHFFB & 1,00 & & & & & & \\
\hline NVB & $0,51 \mathrm{~ns}$ & 1,00 & & & & & \\
\hline PH & $0,80 * *$ & $0,45 \mathrm{~ns}$ & 1,00 & & & & \\
\hline LVB & $0,49 \mathrm{~ns}$ & $0,78^{* *}$ & $0,75^{* *}$ & 1,00 & & & \\
\hline LFB & $0,15 n s$ & $0,65^{*}$ & $0,53 n s$ & $0,88 * * *$ & 1,00 & & \\
\hline NFB & $0,38 n s$ & $-0,04 n s$ & $0,68 * *$ & $0,45 \mathrm{~ns}$ & $0,36 n s$ & 1,00 & \\
\hline NN & $0,64^{*}$ & $0,42 \mathrm{~ns}$ & $0,76 * *$ & $0,65^{*}$ & $0,39 \mathrm{~ns}$ & $0,68 * *$ & 1,00 \\
\hline
\end{tabular}

PHFFB=plant height to first fruiting branch; $\mathrm{NVB}=$ number of vegetative branches;

$\mathrm{PH}=$ plant height; $\mathrm{LVB}=$ length of vegetativebranch; $\mathrm{LFB}=$ length of fruiting branch; NFB= number of fruiting branches; $\mathrm{NN}=$ number of nodes; $* * *, * *, *=$ Significant at $0.1 ; 1$ and $5 \%$ probability levels, respectivelyns $=$ Non-significant 


\section{Discussion}

Use of morphological markers may accelerate the time-consuming procedure of progeny screening resulting from the offspring juvenility phase as a biological barrier and decreased the high expenses caused by a long period of time for nursery field occupation and relative laborious management (Rweyongeza et al., 2004), still to separate the genetic and environmental variations (Dierig et al., 2001). The information on variability and heritability of characters is essential for identifying characters amenable to genetic improvement through selection (Dhamayanathi and Rathinavel, 2010). The results of this study revealed significant variability in morphological traits among the 14 cotton genotypes. We found high heritability for plant height, plant height to first fruiting branch, number of vegetative branches, length of vegetative branch, length of fruiting branch, number of fruiting branches and number of nodes among 14 varieties. Sambamurthy and Rao (1998), and Rao and Reddy (2001) also found high heritability for number of sympodia (fruiting branch). Heritability values vary from 0.720 to 0.999 . This high heritability obtained is due to additive effects that would ensure the selection of offspring to be efficient. It results from this study that the morphological variability observed is heritable and fixable in the offspring (Mandal et al., 2008). Otherwise, the coefficient of correlation found for morphological characters showed a high significant positive correlation between plant height and length of fruiting branch and number of fruiting branches. This suggest that more the cotton plant is high more the number of fruiting branches become important in a normal condition of cultural management practice. Some studies showed positive genotypic and phenotypic correlation between the yield and the height of cotton plant, the height to first fruiting branch, the number of fruiting branches and the number of bolls (Djaboutou et al., 2005).

Based on the results reported here, it should be possible to select cotton genotypes with certain morphological traits, including plant height, height to first fruiting branch, number of vegetative branches, length of vegetative branch, length of fruiting branch, number of fruiting branches, number of nodes that can behave consistently across environments. This information will help breeders to be more successful in developing cultivars with important morphological characteristics. Morphological characteristics are used by breeders in the development of improved cultivars. According to Shortell et al. (2006), plant height is useful characteristics because a low-growing, aggressive spreading cultivar should be able to tolerate lower heights of cut, recover quickly, and fill in damaged areas. Even though there are some discrepancies, the literature indicates that there is sufficient evidence of the positive effect of some morphological characters to use them in the indirect selection and thus increase selection 
efficiency (Ribot et al., 2012).This conventional method of improvement assisted by morphological characters may also be complemented by molecular markers at different stages, to analyze the genetic diversity, select progenitors and identify varieties. Since the characters recommended in this study are easy to measure and have high heritability, the use of molecular markers would not be necessary as the efficient use of molecular markers is obtained when selected characters are highly influenced by the environment. However, molecular markers could be useful if one wishes to accumulate various characters in the same genotype.Since there are molecular techniques which allow selection to be made in early generations, an improvement program could be designed to combine the three selection methods (selection assisted by morphological characters, selection assisted by molecular markers and conventional selection).

\section{Conclusion}

The study revealed high significant variability and heritability in morphological traits among the 14 cotton genotypes. These results are suggesting that the morphological variability observed is heritable and fixable. This conventional method of selection assisted by morphological characters may be complemented and confirmed by molecular markers to analyze the genetic diversity in collection.

\section{References:}

1. Atta B.M., Haq M.A., Shah T.M. 2008. Variation an interrelationships of quantitative traits in chickpea (Cicer aerietinum L.) Pak J Bot 40: 637-647. News Letter. 11 :30-32.bluegrass cultivars and selections grown inNew Jersey. 2005 Rutgers Turfgrass Proc. 37:183-192.

2. Dhamayanathi K. P. M., Manickam S. and Rathinavel K. 2010. Genetic variability studies in Gossypium barbadense L. genotypes for seed cotton yield and its yield components. Electronic Journal of Plant Breeding, 1(4): 961-965

3. Dierig D.A., Ray D.T., Coffelt T.A., Nakayama F.S., Leake G.S. and Lorenz G. 2001. Heritability of height, width, rubber, and latex in guayule (Parthenium argentatum). Ind. Crops Prod.13:229-238.

4. Djaboutou C. M, Alabi S.O., Echewku C. A., and Orakwue F. C. 2005. Variability and inerrelationship of some agronomic and fibre quality traits in multi-adversity cotton (Gossypiumhirsutum L).Agriculturatropicaetsubtropica. 38: 7-12.

5. Hamli S., Bouzerzour H., Benmahammed A., Oulmi A., Kadi K. et Addad D. 2015. Déterminisme génétique des caractères morphophysiologiques liés au rendement chez le blé dur en zone semi-aride 
des hauts plataux sétifiens, Algérie. European Scientific journal April 2015 editio vol.11.No: 12ISSN:1857-7881.

6. INRAB, 2013. Institut National des Recherches Agricoles du Bénin. Rapport Actualisation du programme coton: Identification des contraintes. Janvier 2013. 29p

7. Khalil H., Raza A.B.M., Afzal M., Aqueel M.A., Khalil M.S. and Mansoor M.M. 2015. Effects of plant morphology on the incidence of sucking insect pests complex in few genotypes of cotton. Journal of the Saudi Society of Agricultural Sciences, http://dx.doi.org/10.1016/j.jssas.2015.11.003

8. Mandal S.M.. Chakraborty D. and Gupta K. 2008. Seed size variation: influence on germination and subsequent seedling performance in Hyptis suaveolens (Lamiaceae). Res. J. Seed Sci.1:26-33

9. Rao G. Nageshwara and Reddy M Siva Shantha .2001.Studies on heritability and variability for yield and its components in cotton (G. hirsutum L.,) J Cotton Res. Dev 15(1): 84-86).

10. Ribot G.G., Silva P., Acevedo E. 2012. Morphological and Physiological Traits of Assistance in the Selection of High Yielding Varieties of Durum Wheat (Triticum turgidum L. spp. Durum) for the Rainfed Mediterranean Environments of Central Chile. American Journal of Plant Sciences, 2012, 3, 1809-1819 http://www.SciRP.org/journal/ajps

11. Rweyongeza D.M., Yeh F.C. and Dhir N.K. 2004. Genetic parameters for seasonal height and height growth curves of white spruce seedlings and their implications to early selection. For. Ecol. Mgt. 187:159-172.

12. Sambamurthy J S V and Rao B Rama.1998.Genetic variability and association analysis in parents and hybrid of American cotton. J Cotton Res Dev 12 (20:236-241.

13. Sêkloka E., Lewicki S., Djaboutou M., Sinha M., Hougni A., Kouveglo E., Honton T. 2004. Essais multilocaux, Amélioration génétique classique en station, Amélioration génétique participative et Interactions variétés itinéraires techniques. Rapport annuel, Rapport annuel, Division génétique, CRACF/INRAB, Bénin, 35 p.

14. Shortell R.R., Meyer W.A. and Bonos S.A. 2006. Morphological characteristics of Kentucky bluegrass cultivars and selections grown in New Jersey. Rutgers Turfgrass Proc. 37: 183-192.

15. Shukla R.S., Mishra Y. and Rawat G.S. 2006. Genetic analysis for screening of high temperature and moisture stress tolerance attributes in wheat (Triticum aestivum). Crop Res, 25:63-67. 